\title{
IFN- $\gamma$ signaling, with the synergistic contribution of TNF- $\alpha$, mediates cell specific microglial and astroglial activation in experimental models of Parkinson's disease
}

\section{This article has been corrected since Online Publication and a corrigendum has also been published}

\author{
C Barcia ${ }^{1,2}$, CM Ros $^{1,2}$, V Annese ${ }^{1,2}$, A Gómez $^{1,2}$, F Ros-Bernal ${ }^{1,2}$, D Aguado-Llera ${ }^{1,2}$, ME Martínez-Pagán ${ }^{1}$, V de Pablos ${ }^{1,2}$, \\ E Fernandez-Villalba ${ }^{1,2}$ and MT Herrero*,1,2
}

To through light on the mechanisms underlying the stimulation and persistence of glial cell activation in Parkinsonism, we investigate the function of IFN- $\gamma$ and TNF- $\alpha$ in experimental models of Parkinson's disease and analyze their relation with local glial cell activation. It was found that IFN- $\gamma$ and TNF- $\alpha$ remained higher over the years in the serum and CNS of chronic Parkinsonian macaques than in untreated animals, accompanied by sustained glial activation (microglia and astroglia) in the substantia nigra pars compacta. Importantly, Parkinsonian monkeys showed persistent and increasing levels of IFN- $\gamma \mathrm{R}$ signaling in both microglial and astroglial cells. In addition, experiments performed in IFN- $\gamma$ and TNF- $\alpha$ KO mice treated with MPTP revealed that, even before dopaminergic cell death can be observed, the presence of IFN- $\gamma$ and TNF- $\alpha$ is crucial for microglial and astroglial activation, and, together, they have an important synergistic role. Both cytokines were necessary for the full level of activation to be attained in both microglial and astroglial cells. These results demonstrate that IFN- $\gamma$ signaling, together with the contribution of TNF- $\alpha$, have a critical and cell-specific role in stimulating and maintaining glial cell activation in Parkinsonism. Cell Death and Disease (2011) 2, e142; doi:10.1038/cddis.2011.17; published online 7 April 2011

Subject Category: Neuroscience

Parkinson's disease (PD) is characterized by the rapid and unpredictable loss of dopaminergic neurons located in a small mesencephalic nucleus, the Substantia Nigra pars compacta (SNpc), the cause of which remains unknown. Recent evidence has demonstrated that local inflammation, primarily mediated by glial cells, may contribute to this neuronal degeneration. In fact, post-mortem analysis of the SNpc of PD patients has revealed increased numbers of activated microglial $^{1}$ and astroglial cells, ${ }^{2}$ reflecting persistent inflammation and consequent active nerve degeneration. Likewise, the post-mortem study of a group of drug addicts accidentally intoxicated with 1-methyl-4-phenyl-1,2,3,6-tetrahydropyridine (MPTP), a neurotoxin that specifically kills dopaminergic neurons, showed the same maintained glial reaction in the SNpc many years after the neurotoxin insult. ${ }^{3}$ Importantly, experimentally induced Parkinsonian monkeys showed an identical glial response years after MPTP injection, which was also confined to the SNpc. ${ }^{4,5}$ This indicates that the glial reaction and inflammatory response persist over many years in Parkinsonian subjects (human and non-human primates) despite the absence of any apparent new neurotoxic insult that might induce this state. However, the mechanisms involved in the perpetuation of this glial activation in the SNpc remain unclear.

Pro-inflammatory cytokines are clear candidates to be implicated in the initiation and self perpetuation of glial activation in the brain. ${ }^{6,7}$ Some of these pro-inflammatory cytokines $^{8-10}$ show increased levels in the blood serum of patients with PD and post-mortem analysis of PD patients' brains show a concomitant increase of these cytokines in the nigrostriatal system. ${ }^{10}$ However, the function of this cytokinemediated inflammatory reaction observed in the brain, and also outside the central nervous system (CNS), is poorly understood, as is the way in which normal resting glia become activated. It is known that some cytokines, like interferon- $\gamma$ (IFN- $\gamma$ ) and tumor necrosis factor- $\alpha$ (TNF- $\alpha$ ), may be involved in dopaminergic degeneration, and the absence of either protects dopaminergic neurons in experimental models of PD in mice. . $^{811,12}$ In the present work, we show how IFN- $\gamma$ and $\mathrm{TNF}-\alpha$ are critically involved in the triggering and perpetuation

${ }^{1}$ Clinical and Experimental Neuroscience, University of Murcia, Campus de Espinardo, 30071 Murcia, Spain and ${ }^{2}$ Centro de Investigación Biomédica en Red sobre Enfermedades Neurodegenerativas (CIBERNED), School of Medicine, University of Murcia, Campus de Espinardo, 30071 Murcia, Spain

${ }^{*}$ Corresponding author: MT Herrero, Clinical and Experimental Neuroscience (NiCE-CIBERNED), CIBERNED, School of Medicine, University of Murcia, Campus de Espinardo, 30100 Murcia, Spain. Tel: + 348688846 83; Fax: + 348688841 50; E-mail: mtherrer@um.es

Keywords: Parkinson's disease; inflammation; glial cells; pro-inflammatory cytokines; IFN- $\gamma$; TNF- $\alpha$

Abbreviations: PD, Parkinson's disease; SNpc, Substantia Nigra pars compacta; MPTP, 1-methyl-4-phenyl-1,2,3,6-tetrahydropyridine; CNS, central nervous system; IFN- $\gamma$, interferon- $\gamma$; TNF- $\alpha$, tumor necrosis factor- $\alpha$; HLA-DR, human leukocyte antigen DR; GFAP, glial fibrilary acidic protein; IFN- $\gamma$ R, IFN- $\gamma$ receptor; STAT1, signal transducers activators of transcription type 1; pSTAT1, phosphorylated signal transducers activators of transcription type 1; Iba-1, ionized calcium binding adapter molecule 1

Received 21.9.10; revised 24.1.11; accepted 17.2.11; Edited by D Bano 
of glial activation in vivo, in two animal models of PD. In the first model of chronic Parkinsonian monkeys, we investigate the putative role of IFN- $\gamma$ and TNF- $\alpha$ in a sustained glial inflammatory response in the SNpc. We demonstrate that IFN- $\gamma$ signaling, with the contribution of TNF- $\alpha$, may have a crucial role in stimulating the persistent activation of both microglia and astrocytes in a cell-specific manner. The amount of glial IFN- $\gamma$ increased in the SNpc of Parkinsonian monkeys and was strongly correlated with dopaminergic neuronal degeneration. Importantly, STAT1, a crucial transcription factor activated in response to IFN- $\gamma$, remains phosphorylated locally in glial cells of the SNpc of Parkinsonian monkeys years after MPTP exposure. However, while TNF- $\alpha$ also remained high in MPTP-treated monkeys, it did not correlate so strongly with the dopaminergic loss. In the second model, using $\mathrm{KO}$ mice lacking IFN- $\gamma$ or TNF- $\alpha$, we investigated the particular role of IFN- $\gamma$ and TNF- $\alpha$ in glial activation before dopaminergic neuronal loss could occur and observe that both cytokines are responsible for enhancing the activation of the surrounding glial cells in a reciprocal manner. These results throw light on which cytokines are specifically involved in the glial-mediated inflammatory response in Parkinsonism and suggest two specific therapeutic targets (IFN- $\gamma$ and $\mathrm{TNF}-\alpha)$ to diminish local inflammation in PD.

\section{Results}

Increase of IFN- $\gamma$ and TNF- $\alpha$ in blood serum of Parkinsonian monkeys. Serum samples from 20 young MPTP-treated adult macaques were analyzed to elucidate which pro-inflammatory cytokines may be involved in chronic Parkinsonism. Susceptible MPTP-treated monkeys (Parkinsonian) showed Parkinsonian symptoms, displaying sporadic freezing phenomena and different degrees of bradykinesia and akinesia, while some presented action tremor, paradoxical kinesia and, occasionally, vertical and horizontal saccadic ocular movements. However, some monkeys did not show Parkinsonian symptoms (asymtomatic) despite the numerous MPTP injections (Table 1). Susceptible monkeys also displayed a typical Parkinsonian posture (Figures 1a and b) in contrast to the asymptomatic animals that showed postures similar to controls. Before the postmortem analysis were conducted, several characteristic pro-inflammatory cytokines, IFN- $\gamma$, TNF- $\alpha$, IL-16, IL-6, IL-8 and TNF- $\beta$, were measured in blood serum samples of the MPTP-treated monkeys. Importantly, we observed a sustained increase of IFN- $\gamma$ and TNF- $\alpha$, (Figures $1 \mathrm{c}$ and $\mathrm{d}$ ) in contrast with other proinflammatory cytokines (Supplementary Figure 1) as demonstrated by ELISA measurements. Note that IL-1 $\beta$ was not included in this study because no changes were observed in this cytokine in a previous analysis performed in chronic Parkinsonian monkeys. ${ }^{13}$

Before proceeding with a deeper analysis of these two cytokines in the CNS, we analyzed the level of dopaminergic degeneration and gial activation in the MPTP-treated monkeys. When dopaminergic neuronal loss was analyzed in the SNpc of MPTP-treated monkeys, only monkeys with evident
Table 1 Values of the motor score reached by the monkeys, accumulative dose of MPTP $(\mathrm{mg} / \mathrm{kg})$ of each animal and the time of killing after the last MPTP dose

\begin{tabular}{|c|c|c|c|c|}
\hline Monkey & Sex & Motor Score & $\begin{array}{c}\text { MPTP } \\
\text { Accumulative } \\
\text { dose } \mathrm{mg} / \mathrm{kg}\end{array}$ & $\begin{array}{c}\text { Years after } \\
\text { last MPTP } \\
\text { dose }\end{array}$ \\
\hline C1 & Male & 0.0 & 0 & - \\
\hline $\mathrm{C} 2$ & Male & 0.0 & 0 & - \\
\hline C3 & Female & 0.0 & 0 & - \\
\hline C4 & Male & 0.0 & 0 & - \\
\hline C5 & Male & 0.0 & 0 & - \\
\hline $\mathrm{C} 6$ & Male & 0.0 & 0 & - \\
\hline $\mathrm{A} 1$ & Male & 0.0 & 1.8 & 1 \\
\hline $\mathrm{A} 2$ & Male & 0.0 & 1.8 & 1 \\
\hline A3 & Male & 0.0 & 2.1 & 1 \\
\hline A4 & Male & 0.0 & 1.8 & 1 \\
\hline A5 & Male & 0.0 & 1.8 & 1 \\
\hline A6 & Female & 0.0 & 0.9 & 1 \\
\hline P1 & Male & 3.5 & 1.8 & 1 \\
\hline $\mathrm{P} 2$ & Female & 4.2 & 0.9 & 2 \\
\hline P3 & Male & 5.0 & 1.8 & 1 \\
\hline P4 & Female & 9.2 & 0.9 & 2 \\
\hline P5 & Male & 10.0 & 3.9 & 1 \\
\hline P6 & Male & 10.0 & 4.2 & 5 \\
\hline P7 & Male & 15.0 & 3.6 & 5 \\
\hline P8 & Male & 17.0 & 2.1 & 1 \\
\hline
\end{tabular}

Abbreviations: A, asymptomatic animals; $\mathrm{C}$, control animals; $\mathrm{P}$, Parkinsonian animals
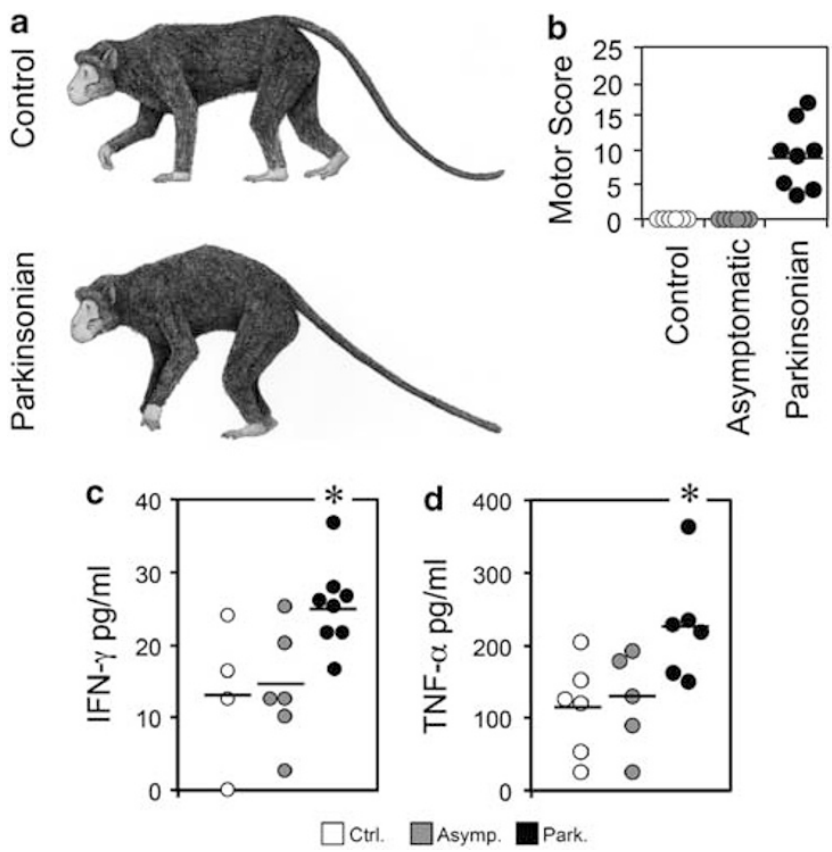

Figure 1 Persistent increase of IFN- $\gamma$ and TNF- $\alpha$ in chronic Parkinsonian monkeys. (a-d) Artist's sketch (a) of the typical gait posture of a normal monkey (control) compared with the characteristic Parkinsonian posture (Parkinsonian). Parkinsonian monkey posture is characterized by curvature of the trunk and rigidity of the limbs, together with rigidity of the tail (drawings by C.B). (b) Graphs of the motor score impairment reached by the MPTP-treated monkeys included in the study. Some animals, despite MPTP administration, did not show symptoms (asymptomatic). (c) Levels of IFN- $\gamma$ measured by ELISA in serum increase in Parkinsonian monkeys. (d) Levels of TNF- $\alpha$ measured by ELISA in serum are increased in Parkinsonian monkeys. ${ }^{*} P<0.05$ respect to non-Parkinsonian

Parkinsonian symptoms presented a high degree of dopaminergic neuronal loss (Supplementary Figure 2a). However, asymptomatic monkeys showed a certain, non-significant loss 
with respect to control animals (Supplementary Figure 2a). Parkinsonian animals showed increased levels of both microglial and astroglial activation, as demonstrated, by the expression of HLA-DR and GFAP markers, respectively, and by phenotypical changes in both cell types (Supplementary Figures $2 b, 2 c$ and 3 ). The group of animals killed 5 years after the last MPTP dose showed slightly higher glial activation, although the number of animals in this group (5 years) was too small $(n=2)$ for any statistical differences to be established. Moreover, the animals from this group had higher motor scores and suffered greater dopaminergic neuronal loss, which may bias any observations. Previous studies have shown that glial activation maintains similar levels despite acute or chronic protocols of MPTP administration. ${ }^{14}$

Taken together, these results confirm that in our model of Parkinsonian macaques, glial cells remain activated over a number of years. However, since it was thought that proinflammatory cytokines may be involved in glial cell activation, we proceeded to analyze IFN- $\gamma$ and TNF- $\alpha$ levels in the CNS of the Parkinsonian monkeys.

Increase of IFN $-\gamma$ in the CNS of Parkinsonian monkeys. Sections of the SNpc were stained with antibodies against IFN- $\gamma$ and western blot analysis was performed in homogenates of the SNpc to test the specificity of the antibodies and to quantify the amount of IFN- $\gamma$. Few IFN- $\gamma^{+}$ cells were seen in the control animals, whereas, MPTP. treated animals showed a dramatic increase in IFN- $\gamma^{+}$cells in the SNpc (Figures 2a and b). Furthermore, this increase was more pronounced in animals with evident clinical symptoms. Western blot analysis demonstrated the specificity of the IFN- $\gamma$ antibody, and pointed to a similar increase of IFN- $\gamma$ in the SNpc of Parkinsonian monkeys (Figure 2c). Importantly, the amount of IFN- $\gamma$ was closely correlated with motor impairment and dopaminergic cell death (Table 2). There was also a correlation with microglial activation, especially as regards phenotypical changes, but a weak correlation with astroglial activation (Table 2).

To identify the IFN- $\gamma$-expressing cell type, adjacent sections were stained with an antibody against IFN- $\gamma$ combined with antibodies against Iba- 1 or GFAP. Surprisingly, IFN- $\gamma$ immunoreactivity was primarily observed in the microglia (Iba- ${ }^{+}$cells), but was absent in the astroglia (GFAP ${ }^{+}$cells) (Figure 2d), which suggests that microglial cells may produce/ release or accumulate IFN- $\gamma$ in the SNpc of Parkinsonian monkeys. Interestingly, when the IFN- $\gamma$-expressing microglial cells were analyzed by detailed confocal microscopy, some microglial cells showed peri-nuclear IFN- $\gamma$ staining (Figure 2e1), while other cells, with an activated morphology (increased cell body size and a higher number of ramifications), expressed IFN- $\gamma$ throughout the entire cytoplasm (cell body and ramifications) (Figure $2 \mathrm{e} 2$ ). In addition, this increase in IFN- $\gamma$-expressing cells corresponded to a higher percentage of microglial cells that express IFN- $\gamma$ in chronic Parkinsonism (Figure 2f).

Evidence of IFN- $\gamma$ R signaling by glial cells in the SNpc of chronic Parkinsonian monkeys. Given the increased expression of IFN- $\gamma$ in the SNpc of chronic Parkinsonian monkeys, the expression of IFN- $\gamma$ receptor (IFN- $\gamma \mathrm{R}$ ) was studied in monkey brain sections to ascertain which cell types were affected by IFN- $\gamma$ signaling. It was observed that both microglial cells and astroglial cells are able to express IFN- $\gamma \mathrm{R}$, as demonstrated by multiple immuno-fluorescence (Figure 3). Most importantly, as the phosphorylation of STAT1 is essential for responsiveness to IFN- $\gamma$, through stimulation of the IFN- $\gamma \mathrm{R}$, we analyzed the expression of phosphorylated STAT1 (pSTAT1) in the SNpc of chronic Parkinsonian monkeys, finding that the number of pSTAT1expressing cells was greatly increased in Parkinsonian animals compared with the control (Figures $4 a$ and b). Furthermore, we also observed that the increase of pSTAT1 expression was specific for the SNpc and was not observed in other uninvolved brain regions (Supplementary Figure 4). In addition, the expression of pSTAT1 was seen in both microglial and astroglial cells (Figures $4 \mathrm{c}$ and $\mathrm{d}$ ), which demonstrates that IFN- $\gamma$ signaling may be involved in the sustained glial activation of both cell types in the SNpc.

TNF- $\alpha$ increases in the CNS of Parkinsonian monkeys. As stated above, we observed a sustained increase of TNF- $\alpha$ in chronic Parkinsonian monkeys, as demonstrated by ELISA measurements in serum. Immunohistochemistry in brain sections using an antibody against $\mathrm{TNF}-\alpha$ revealed a pronounced increase of TNF- $\alpha^{+}$cells in the SNpc of Parkinsonian monkeys. (Figures $5 \mathrm{a}$ and b). Western blot analysis of homogenates of the SNpc corroborated the specificity of the antibody and revealed that MPTP-treated animals presented high levels of TNF- $\alpha$, the degree of which was correlated with their Parkinsonian symptoms and with the level of neuronal degeneration (Figure $5 \mathrm{c}$ and Table 2). However, poor correlation was seen between glial activation and the amount of TNF- $\alpha$ measured by western blot (Table 2) probably because of the similar levels shown by asymptomatic and Parkinsonian monkeys. To identify the cell type-expressing TNF- $\alpha$, adjacent sections of the SNpc were also stained with the antibody against TNF- $\alpha$ combined with antibodies against Iba-1 or GFAP. Confocal images demonstrated that TNF- $\alpha^{+}$immunoreactivity was primarily observed in astrocytes, but was very faint or absent in microglia (Figures 5d and e). Moreover, this increase in TNF- $\alpha$-expressing cells corresponded to a higher percentage of astrocytes that express $\mathrm{TNF}-\alpha$ several years after MPTP insult than observed in intact animals (Figure 4f).

IFN- $\gamma$ is crucial for microglial activation and TNF- $\alpha$ exerts a synergistic effect. On the basis of the observations described above and the fact that IFN- $\gamma$ is highly expressed in microglia and TNF- $\alpha$ is highly expressed in astroglia in the SNpc of chronic Parkinsonian monkeys, we used a model of glial activation in $\mathrm{KO}$ mice lacking IFN- $\gamma$ or TNF- $\alpha$ to ascertain whether the absence of one of these cytokines may have a differential impact on glial activation. Taking advantage of the fact that MPTP exerts a rapid glial activation in mice within $24 \mathrm{~h}$ (Supplementary Figure 5), KO mice were injected with a single dose of MPTP $(20 \mathrm{mg} / \mathrm{kg})$ and killed before dopaminergic neuronal loss could be observed $(24 \mathrm{~h}$ after MPTP). IFN- $\gamma(-/-)$, TNF- $\alpha(-/-)$ and wild-type mice of the 

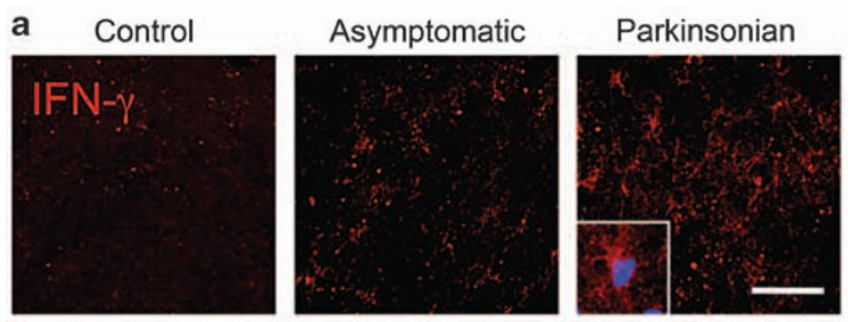

b
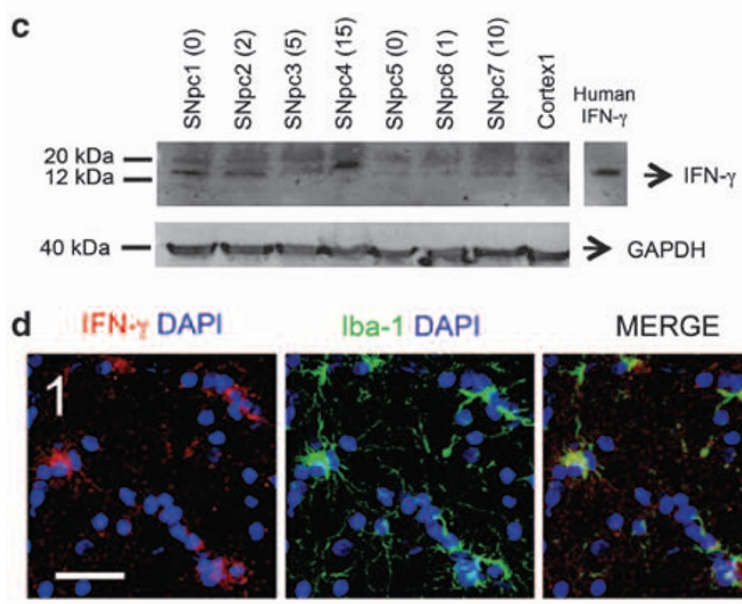

|ba-1 DAPI
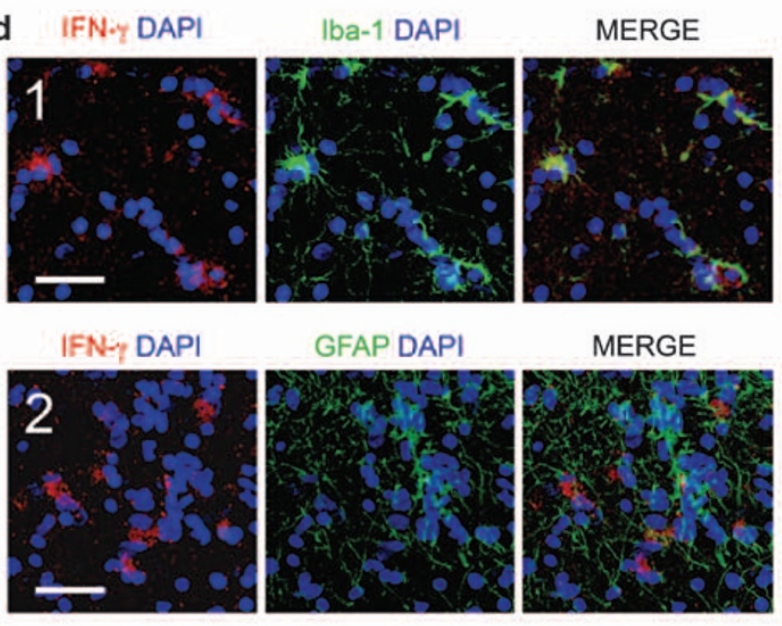

GFAP DAPI

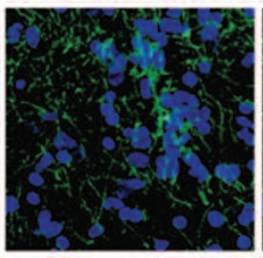

\section{MERGE}
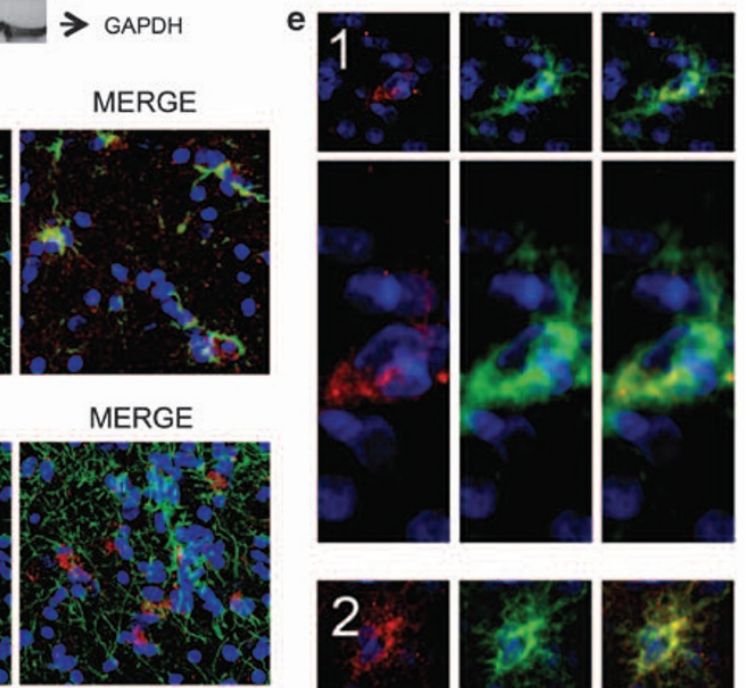

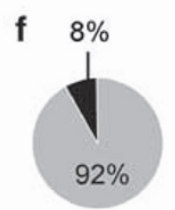

Control

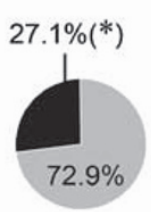

Asymp.

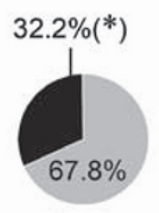

Park.
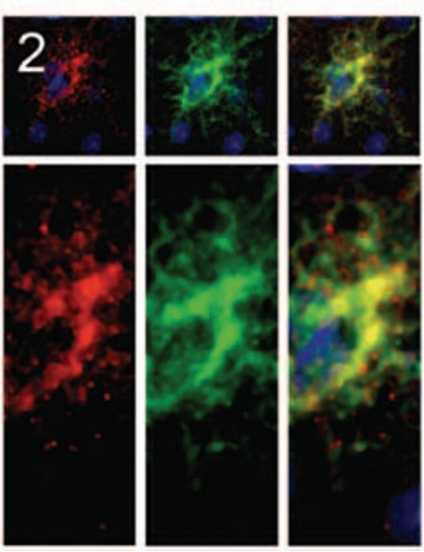

Figure 2 Increase of IFN- $\gamma$ in the SNpc of Parkinsonian monkeys. (a-f): Increase of IFN- $\gamma^{+}$cells in brain sections of the SNpc of Parkinsonian monkeys. (a) Confocal images of immunofluorescence against IFN- $\gamma$ revealed a higher number of IFN- $\gamma^{+}$cells in MPTP-treated animals. Scale bar: $100 \mu$ m. (b) The density of cells was estimated by stereological criteria and a significant increase in IFN- $\gamma^{+}$cells was observed in MPTP-treated animals. (c) Western blot of IFN- $\gamma$ from monkey brain samples. Tissue of the SNpc from seven different monkeys (1-7) is shown. The Parkinsonian motor score of the monkeys is indicated between brackets. GAPDH was used as house-keeping protein. The analysis of the optical density of all the studied monkeys, normalized with GAPDH, is represented in Table 2. (d) Multiple fluorescence labeling revealed that IFN- $\gamma$ (red) co-localize with microglial marker Iba-1 (green) (1). However, astrocyte marker GFAP (green) did not co-localize with IFN- $\gamma$-expressing cells (red) (2). DAPI staining was used to mark the cell nuclei (Blue). Scale bar: $50 \mu \mathrm{m}$. (e) Higher magnification of two representative IFN- $\gamma^{+}$microglial cells. Some of the microglial cells with resting phenotype (1) presented IFN- $\gamma$ staining mainly confined to the cytoplasm (red) surrounding the cell nucleus (Blue). Other microglial cells with activated phenotype (2) presented IFN- $\gamma$ staining through the whole cytoplasm. (f) Percentage of IFN- $\gamma$-expressing microglia (black pie portion (Iba- $1^{+} / / F N-\gamma^{+}$cells)) over the rest of the microglial population (gray pie portion (Iba- $1^{+} / \mathrm{IFN}-\gamma^{-}$cells)) in the three group of animals. ${ }^{*} P<0.05$ (one-way ANOVA and Tukey's test)

same age and background (C57BL6) were injected with MPTP and killed $24 \mathrm{~h}$ later. Microglial and astroglial activation were analyzed with confocal microscopy, bearing in mind the criteria described in the Material and Methods section (Supplementary Figure 6). Before dopaminergic loss could be observed (Figure 6a), wild-type mice (C57BL-6) showed a specific activation of microglial cells in the SNpc, characterized by an increase in $F 4 / 80$ expression (Figure 6b), a pronounced increase in cell body size (Figures $6 c$ and d) and also by an increased number of 
Table 2 Pearson's correlation between the amount of cytokines (IFN- $\gamma$ or TNF- $\alpha$ ) measured in the SNpc of monkeys by western blot and (1) the motor impairment, (2) dopaminergic cell death and (3) activation of microglia or astroglia, measured by the number of activated cells (HLA-DR for microglia and GFAP for astroglia) or the change of glial phenotype

\begin{tabular}{|c|c|c|c|c|c|c|}
\hline & \multirow[b]{2}{*}{ Motor impairment } & \multirow[b]{2}{*}{ Dopaminergic cell death } & \multicolumn{2}{|c|}{ Microglial activation } & \multicolumn{2}{|c|}{ Astroglial activation } \\
\hline & & & Number HLA-DR & Phenotype & Number of GFAP & Phenotype \\
\hline $\begin{array}{l}\text { IFN- } \gamma \\
\text { TNF- } \alpha\end{array}$ & $\begin{array}{l}0.91^{\star *} \\
0.68^{+}\end{array}$ & $\begin{array}{l}-0.99^{\star \star \star} \\
-0.63^{+}\end{array}$ & $\begin{array}{l}0.81^{+} \\
0.55 \mathrm{~ns}\end{array}$ & $\begin{array}{l}0.95^{\star \star \star} \\
0.47 \mathrm{~ns}\end{array}$ & $\begin{array}{l}0.51 \mathrm{~ns} \\
0.38 \mathrm{~ns}\end{array}$ & $\begin{array}{l}0.89^{\star} \\
0.57 \mathrm{~ns}\end{array}$ \\
\hline
\end{tabular}

Values of significance for Pearson's correlation: ${ }^{\text {ns }} P=0.1$ (non-significant), ${ }^{+} P \leq 0.05,{ }^{\star} P<0.02,{ }^{* \star} P<0.01,{ }^{\star \star \star} P<0.001$

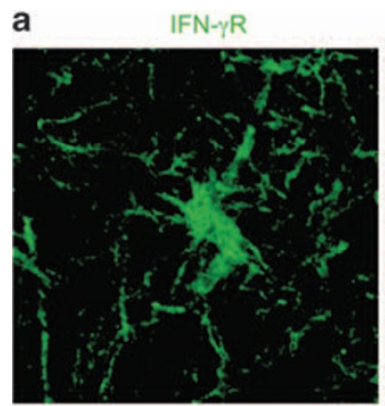

b

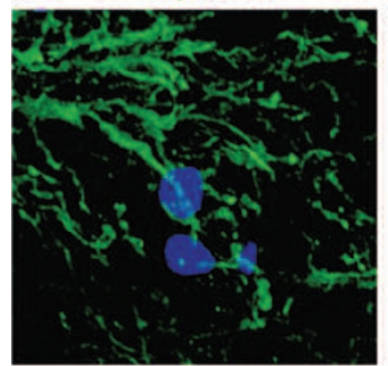

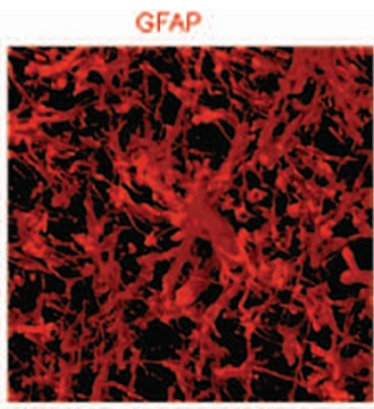

|be-1/DAP|

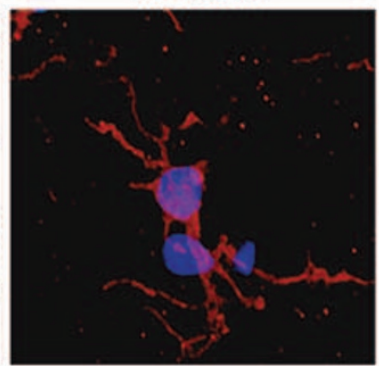

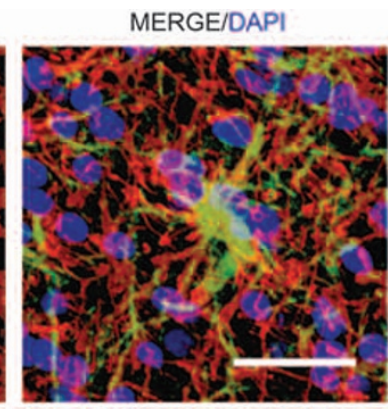

MERGE/DAPI

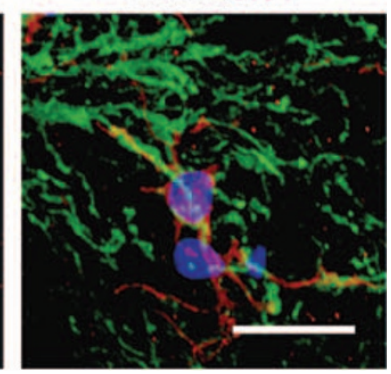

Figure 3 Microglial and astroglial cells express IFN- $\gamma$ R in the SNpc of MPTP-treated monkeys. ( $\mathbf{a}$ and $\mathbf{b}$ ) Sections of the SNpc of MPTP-treated monkeys were immunostained for IFN- $\gamma$ R (Green), combined with either astrocyte marker GFAP (Red in a) or microglial marker lba-1 (Red in b) and counterstained with DAPI (Blue). Scale bars: in a, $50 \mu \mathrm{m}$; in $\mathbf{b}, 40 \mu \mathrm{m}$

primary and secondary branches and terminal tips (Figure 6e).

Importantly, in mice lacking IFN- $\gamma(\operatorname{IFN}-\gamma(-/-))$, microglial activation was severely affected. First of all, no changes in the number of $\mathrm{F} 4 / 80^{+}$cells was observed and, second, the size of the microglial cells did not increase after MPTP treatment (Figures 6b-e and Table 3). However, the number of branches did increase in IFN- $\gamma$ KO mice, which suggests that this phenotypical change in the microglia is not dependent on this cytokine. On the other hand, in mice lacking TNF- $\alpha$ (TNF$\alpha(-/-))$, the microglial cells were slightly activated, as seen from a slight increase in numbers ( $\mathrm{F} 4 / 80^{+}$cells) and size and also an increased number of branches and tips (Figures $6 \mathrm{~b}-\mathrm{e}$ and Table 3 ), suggesting that TNF- $\alpha$ has a synergistic coadjuvant role in activating microglia.

IFN- $\gamma$ signaling with TNF- $\alpha$ contribution is necessary for astroglial activation. Concomitantly, we observed that wild-type mice (C57BL-6) show a specific activation of astroglial cells in the SNpc, characterized by an increased number of GFAP ${ }^{+}$cells (Figures $6 \mathrm{~b}$ and $\mathrm{c}$ ), a larger cell body size (Figures $6 \mathrm{c}$ and $\mathrm{d}$ ) and also by an increased number of secondary branches and terminal tips (Figures $6 \mathrm{c}-\mathrm{e}$ ).
Importantly, the absence of IFN- $\gamma$ or TNF- $\alpha$ prevented any increase in the number of astrocytes (GFAP ${ }^{+}$cells) in the SNpc after MPTP treatment (Figure 6b). On the other hand, reactive GFAP cells showed the characteristic size change after MPTP treatment and a slight increase in the number of secondary branches and tips in IFN- $\gamma \mathrm{KO}$ animals, which suggests that IFN- $\gamma$ is not necessary for these morphological changes (Figures $6 b-e$ ). However, the area occupied by GFAP $^{+}$cells and the number of branches and terminal tips did not change in mice lacking TNF- $\alpha$ (TNF- $\alpha(-/-)$ ), demonstrating that TNF- $\alpha$ is crucial for the characteristic phenotypical changes of astrocytes after MPTP intoxication (Figures 6d and e).

\section{Discussion}

In the present work, we show that the persistent release of IFN- $\gamma$ and TNF- $\alpha$, among other pro-inflammatory cytokines, is a crucial factor for perpetuating glial activation in Parkinsonism (Figures 1, 2, 5, 6 and Supplementary Figure 1) and importantly, may contribute to neuronal degeneration. This is important, as it narrows down to two the putative specific targets to be hit to diminish the glial-mediated inflammatory 
a

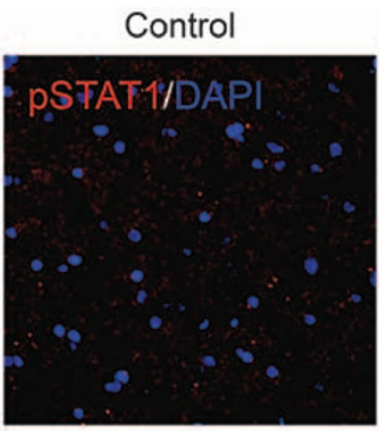

b

b

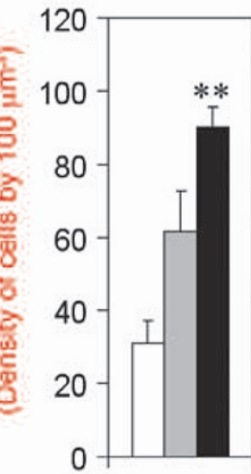

e

$\square$ Ctrl. $\square$ Asymp. $\square$ Park.

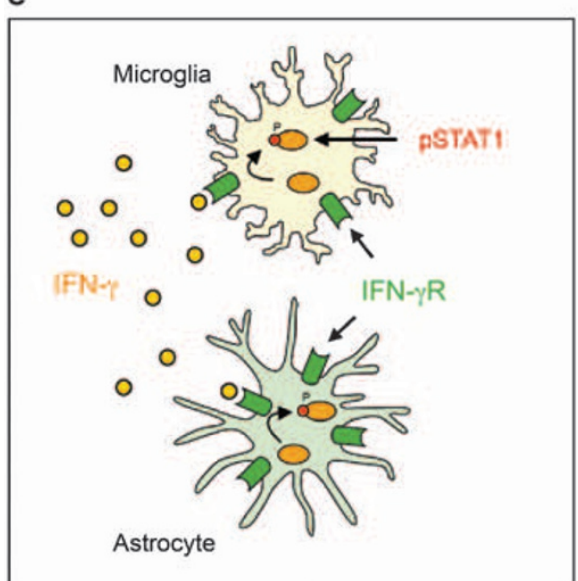

Asymptomatic

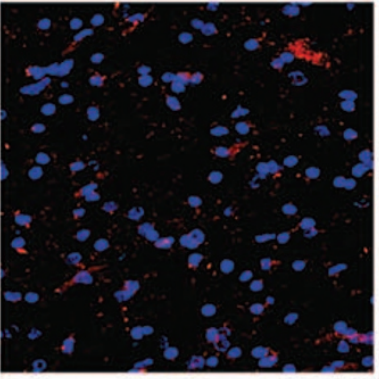

c
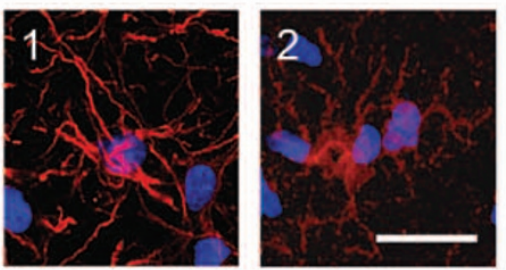

d GFAP

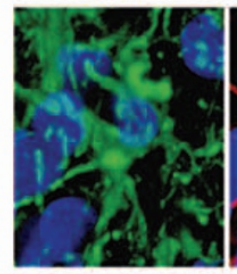

PSTAT1

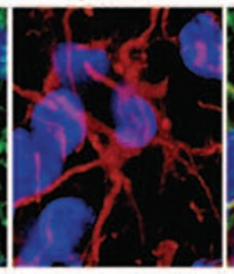

MERGE
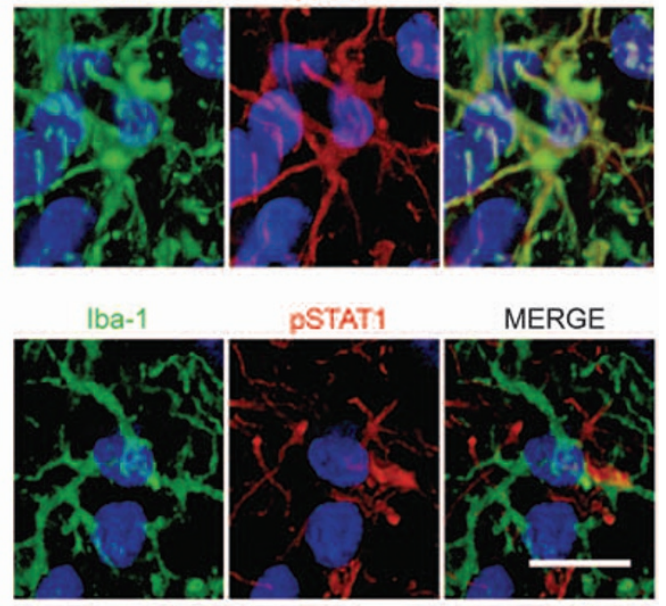

Parkinsonian

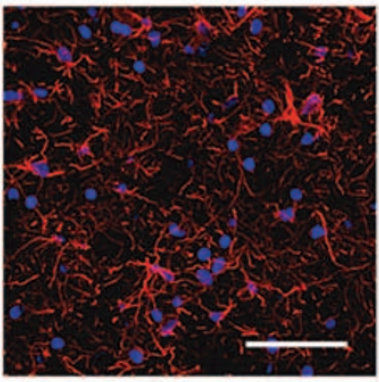



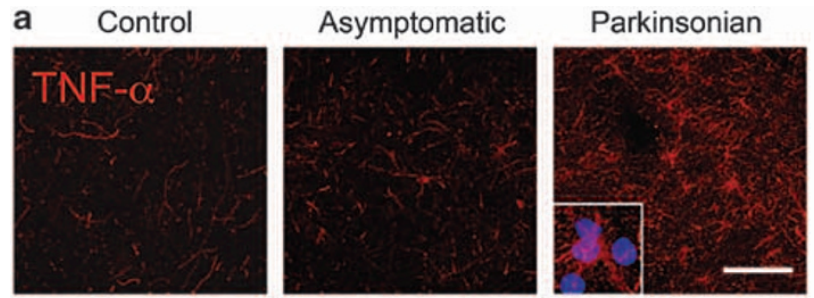

b

C
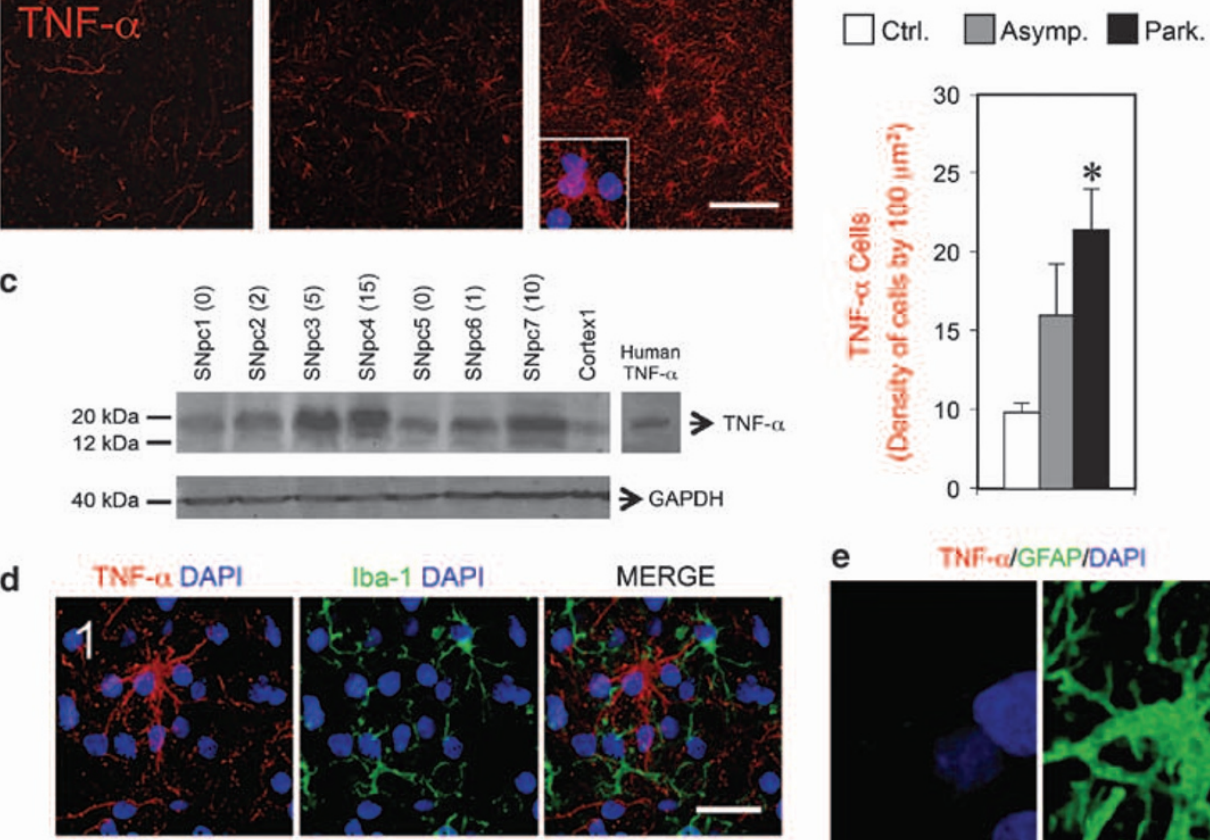

|ba-1 DAP|
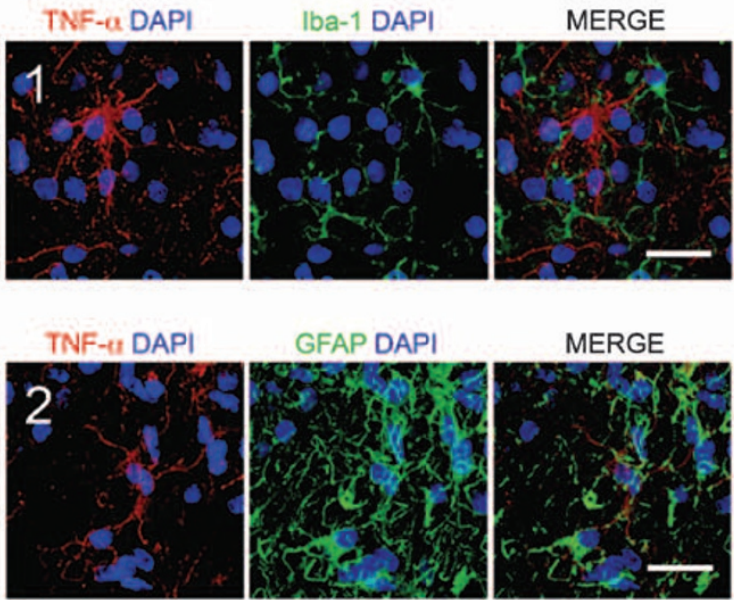

MERGE

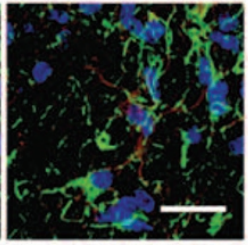

f
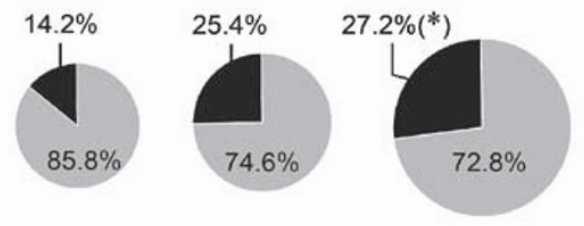

Asymp.

Park.
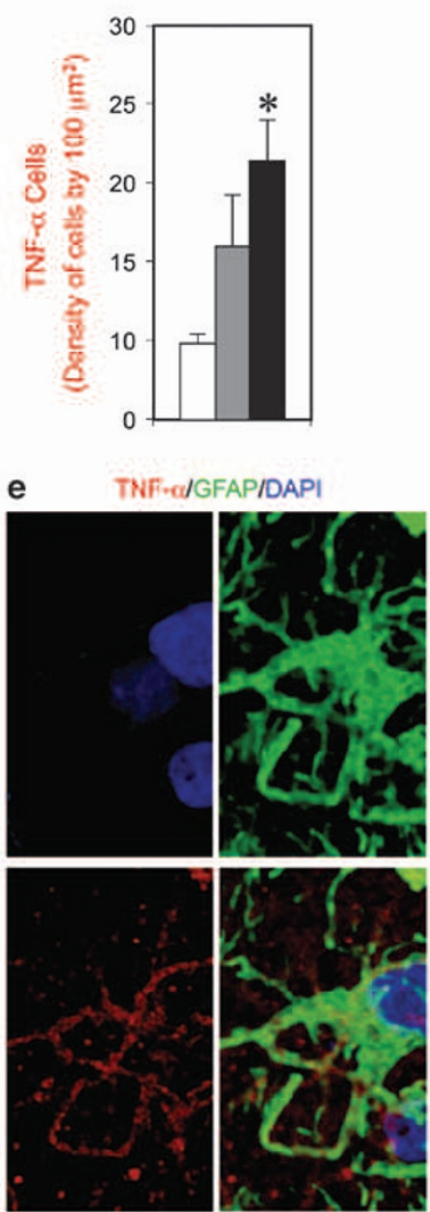

Control

GFAP $/ N$ TF- $\alpha$

GFAPITNF- $\alpha^{+}$

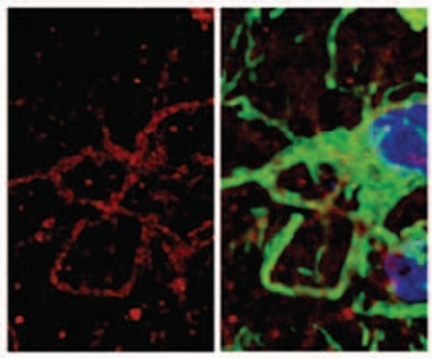

Figure 5 Persistent increase of TNF- $\alpha$ in the CNS of chronic Parkinsonian monkeys. (a-f) Increase of TNF- $\alpha^{+}$cells in the SNpc of Parkinsonian monkeys. (a) Confocal images of immunofluorescence against TNF- $\alpha$ revealed higher levels in Parkinsonian animals. Scale bar: $100 \mu \mathrm{m}$. (b) The density of cells was estimated by stereological criteria and a significant increase of TNF- $\alpha^{+}$cells were observed in Parkinsonian animals. (c) Western blot of TNF- $\alpha$ from monkey brain samples. Tissue of the SNpc from seven different monkeys (1-7) is shown. The Parkinsonian motor score of the monkeys is indicated between brackets. GAPDH was used as house-keeping protein. TNF- $\alpha$ was specifically detected in the expected band in the SNpc of MPTP-treated monkeys. The quantification of the optical density of all the analyzed monkeys, normalized with GAPDH, is represented in Table 2. (d) Multiple fluorescence labeling revealed that TNF- $\alpha$ (red) did not co-localize with microglial marker lba-1 (green) (1). However, astrocyte marker GFAP (green) co-localized with TNF- $\alpha$-expressing cells (red) (2). DAPI staining was used to mark the cell nuclei (Blue). Scale bar: $25 \mu \mathrm{m}$. (e) Higher magnification of a representative TNF- $\alpha^{+}$astrocyte. (f) Percentage of TNF- $\alpha$-expressing astrocytes (black pie portion (GFAP ${ }^{+} / \mathrm{TNF}-\alpha^{+}$cells)) over the rest of the astroglial population (gray pie portion (GFAP ${ }^{+} /$TNF- $^{-}$cells)) in the three group of animals. ${ }^{*} P<0.05$ (one-way ANOVA and Tukey's test)

phenotypical changes in microglia (Table 2). This activation may be induced and perpetuated by initiation of the STAT1 pathway through stimulation of the IFN- $\gamma \mathrm{R}$ present in microglial and astroglial cells ${ }^{15,16}$ (Figure 3 ). This is consistent with the evidence of STAT1 phosphorylation observed in astrocytes and microglial cells in the SNpc of Parkinsonian monkeys (Figure 4) and is concordant with previous results reported in other inflammatory scenarios in the CNS .
On the other hand, besides the action of IFN- $\gamma$, the contribution of TNF- $\alpha$ also seems to be important for glial activation in Parkinsonism, especially for astrocytes. This is consistent with the fact that astrocytes are able to release TNF- $\alpha$ and, at the same time, can also be stimulated by TNF- $\alpha$ in vitro. ${ }^{17,18}$ This activation may be particularly related with the morphology of astrocytes, because the lack of TNF- $\alpha$ results in the absence of phenotypical changes after MPTP insult in 

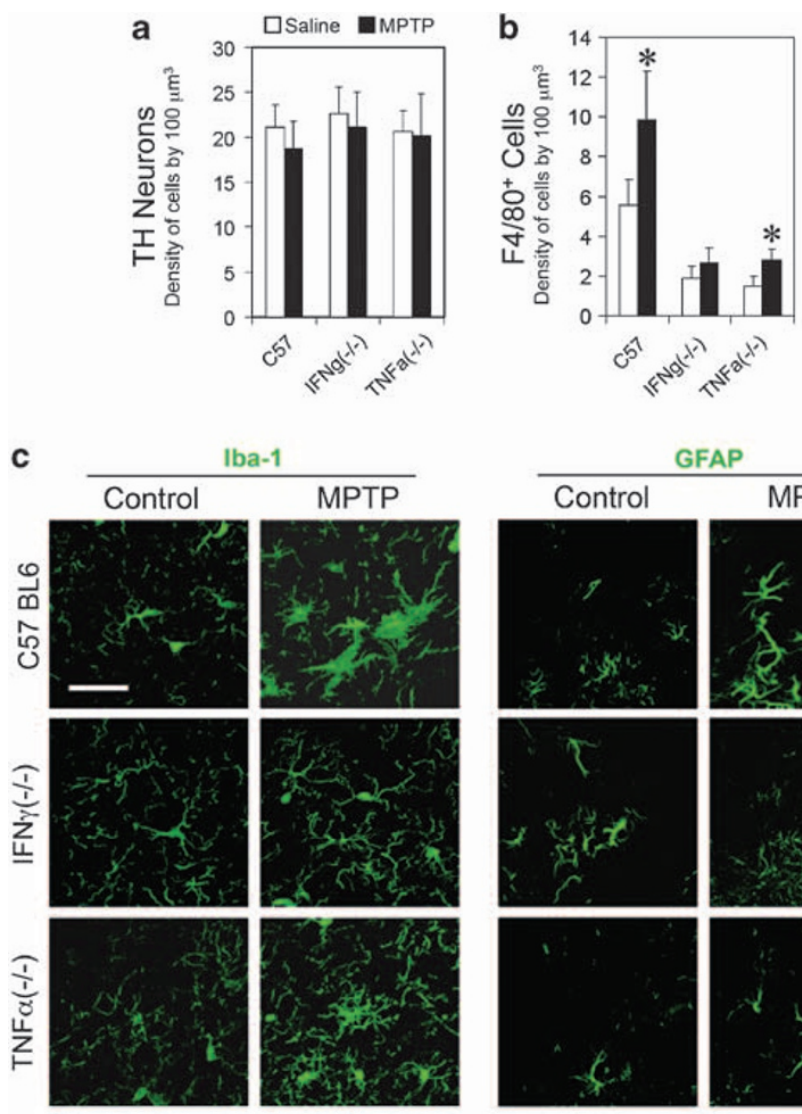

e
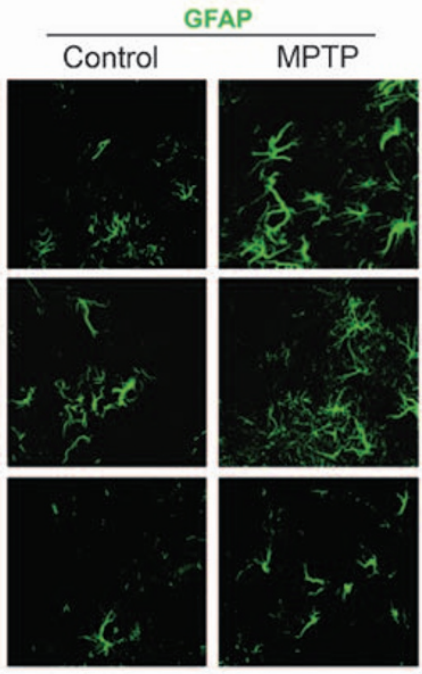
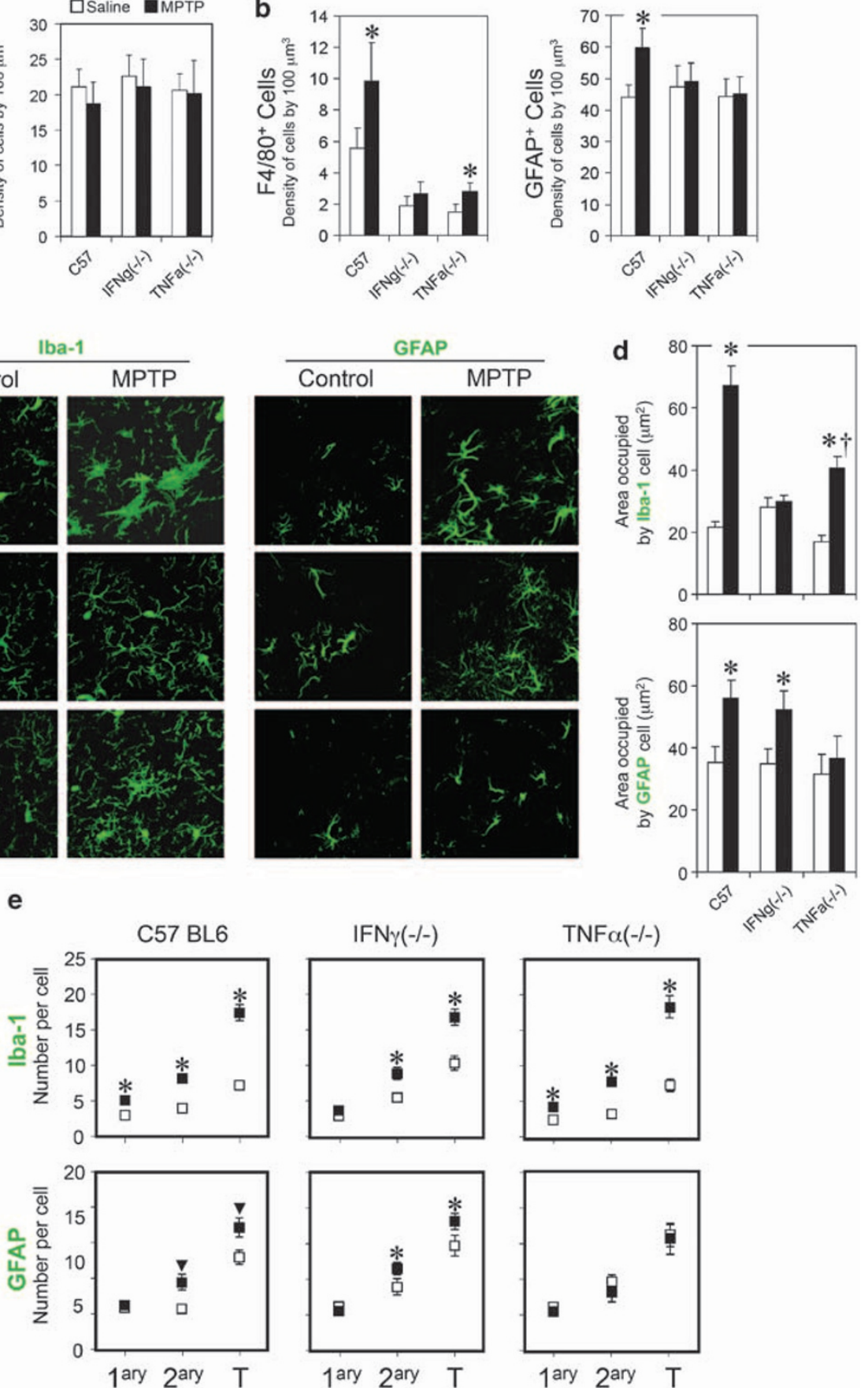

$\operatorname{IFN} \gamma(-/-)$
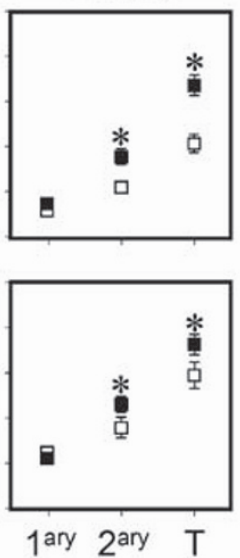

$\operatorname{TNF} \alpha(-/-)$
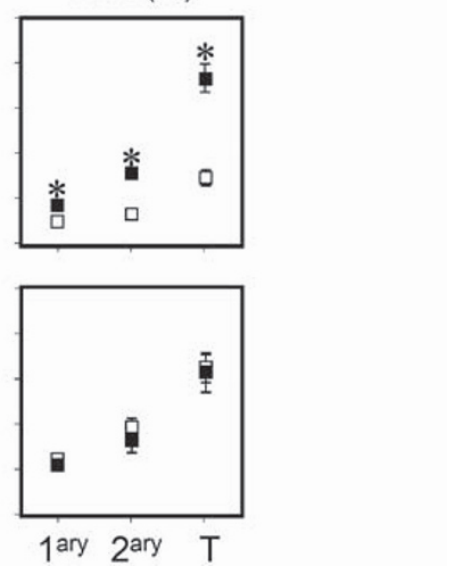

Figure 6 IFN- $\gamma$ and TNF- $\alpha$ have a cell specific function in microglial and astroglial activation. (a-f) Activation of the microglia depends on IFN- $\gamma$ and activation of the astrocytes depends on TNF- $\alpha$. (a) Quantification of $\mathrm{TH}^{+}$neurons in the SNpc revealed no significant reduction of dopaminergic neurons in any of the experimental groups $24 \mathrm{~h}$ after MPTP. (b) Quantification of the number of F4/80 ${ }^{+}$microglial cells and GFAP ${ }^{+}$astroglial cells. In the absence of IFN- $\gamma$, no increase in the number of F4/80 ${ }^{+}$or $\mathrm{GFAP}^{+}$cells was observed after MPTP treatment. In the absence of TNF- $\alpha$, a slight increase of $F 4 / 80^{+}$cells was observed, but no changes were noted in the number of $\mathrm{GFAP}^{+}$cells. ${ }^{*} P<0.05$ (one-way ANOVA and Tukey's test). (c) Confocal pictures of microglial cells (lba-1) and astroglial cells (GFAP) in the SNpc of wild type mice (C57 BL6), IFN- $\gamma$ KO mice (IFN $\gamma(-/-)$ ) and TNF- $\alpha$ KO mice (TNF- $\alpha(-/-)$ ). Scale bar: $30 \mu \mathrm{m}$. (d) Quantification of the area occupied by lba-1 demonstrates that the size of microglial cells (Iba-1) increases significantly after MPTP treatment. However, in the absence of IFN- $\gamma$, the microglial cells do not change their size. In TNF- $\alpha(-/-)$ mice, microglial cells also increase their size, but to a lesser extent. Quantification of the area occupied by GFAP demonstrated that the size of astroglial cells increases after MPTP treatment. In the absence of IFN- $\gamma$, astroglial cells also increase their size after MPTP; however, in the absence of TNF- $\alpha$, astroglial cells remain unchanged after MPTP. ${ }^{*} P<0.01$ with respect to control saline values, ${ }^{\dagger} P<0.01$ with respect to wild type C57 MPTP (one-way ANOVA and Tukey's test). (e) Quantification of primary branches (1ary), secondary branches (2ary) and terminal tips (T) in microglial (Iba-1) and astroglial cells (GFAP). Both microglial and astroglial cells change their phenotype $24 \mathrm{~h}$ after MPTP treatment in wild-type animals (C57BL6). In animals without IFN- $\gamma(\operatorname{IFN} \gamma(-l-))$, microglial cells show no changes in primary branches, but increased numbers of secondary branches and terminal tips. In TNF- $\alpha$ KO animals (TNF $\alpha(-/-)$ ), microglial cells show increased numbers of primary, secondary branches and T. However, astroglial cells remain unchanged in TNF- $\alpha(-/-)$ mice $24 \mathrm{~h}$ after MPTP. ${ }^{*} P<0.01, \nabla P<0.05$ (one-way ANOVA and Dunnett's test) 
Table 3 Summary of the results obtained from the analysis of microglia and astroglial activation in the SNpc after MPTP treatment of wild type (C57BL6), IFN $\gamma(-/-)$ and TNF $\alpha(-/-)$ mice

\begin{tabular}{lcc}
\hline Microglia & Increase of $\mathbf{F} \mathbf{4} / \mathbf{8 0}^{+}$cells & Increase in \# of branches and tips \\
\hline C57BL6 & +++ & +++ \\
IFN $\gamma(-/-)$ & - & ++ \\
TNF $\alpha(-/-)$ & + & +++ \\
Astroglia & Increase of GFAP cells & Increase in \# of branches and tips \\
\hline C57BL6 & +++ & +++ \\
IFN $\gamma(-/-)$ & - & +++ \\
TNF $\alpha(-/-)$ & - & + \\
\hline
\end{tabular}

mice (Figure 6). It seems that TNF- $\alpha$ acts in a synergistic way, probably enhancing glial activation by the stimulation of the TNF- $\alpha \mathrm{R}$ present in astroglial cells, ${ }^{19}$ which suggests that astrocyte activation may be also relevant for the activation of surrounding astrocytes.

TNF $-\alpha$ and IFN $-\gamma$ showed high levels over several years following MPTP treatment in our monkeys (Figures 2 and 5) as occurs in PD patients, ${ }^{8-10,20}$ which may have contributed to the long-term glial activation observed and consequently to dopaminergic loss. Importantly, the amounts of both, IFN- $\gamma$ and TNF- $\alpha$ in the SNpc correlate with the degree of neurodegeneration and motor impairment (Table 2). In line with this, previous reports showed that centrally and systemically circulating cytokines may exacerbate neurodegeneration in Parkinsonian rats, suggesting that the expression of cytokines in the CNS and also in the blood stream may be crucial for full glial activation and dopaminergic degeneration. $^{21}$

Unlike in primates, mice do not show such persistently increased cytokine levels in the blood $24 \mathrm{~h}$ after MPTP insult (Supplementary Figure 5), which may be consistent with transient glial activation. ${ }^{22-24}$ In fact, previous reports have shown that MPTP-treated mice merely show a transitory increase in pro-inflammatory cytokines from $24 \mathrm{~h}$ to $72 \mathrm{~h}$ after MPTP insult, which may explain why only some pools of our mice showed increased levels of IFN- $\gamma$ and TNF- $\alpha$ after MPTP (Supplementary Figure 5). ${ }^{22-25}$ Furthermore, the perceptible, but transient increase in cytokine levels in mice after MPTP is also dependent on the MPTP treatment regime, and may only be observed in protocols involving chronic administration. ${ }^{23}$

Our results also suggest that glial cells may be one of the main cells responsible for IFN- $\gamma$ and $\mathrm{TNF}-\alpha$ release in the CNS. We first demonstrated that IFN- $\gamma$ is highly increased in the SNpc, as demonstrated by immunohistochemistry and western blot analysis. Surprisingly, microglial cells and not astrocytes showed a high degree of IFN- $\gamma$ expression in the SNpc of monkeys (Figure 2). The possibility of a role for cells of myeloid origin, such as macrophages/microglia, as an additional source of IFN- $\gamma$ is controversial and has received little attention (for review on this matter see ref. 26). In depth studies have shown strong evidence that macrophages/ microglia are able to synthesize IFN- $\gamma$ mRNA and produce IFN- $\gamma$ protein in both resting and activated states. ${ }^{27,28}$ After activation, macrophages/microglia show higher levels of IFN- $\gamma$ and its release may have a crucial role in the activation of neighboring cells and conduct the local inflammatory response. ${ }^{26-28}$ Importantly, the detection and imaging of
IFN- $\gamma$ protein in resting or activated macrophages has been elusive, and confocal immunofluorescence is the preferable technique for its cell-associated detection (see review ref. 26, pg. 288, 2nd paragraph).

Interestingly, the expression of IFN- $\gamma$ can be observed in both microglial cells with or without an activated phenotype (Figure 2e). IFN $-\gamma^{+}$microglial cells with resting phenotype show peri-nuclear staining of IFN- $\gamma$ (Figure 2e1). However, IFN $-\gamma^{+}$microglial cells with activated phenotype show a high content of IFN- $\gamma$ in the cytoplasm, suggesting that highly activated microglia may be able to produce, release or accumulate large amounts of IFN- $\gamma$ (Figure 2e2). Control animals showed a small percentage of IFN- $\gamma$-expressing microglia, which significantly increased in MPTP-treated monkeys (Figure 2f).

In contrast, TNF- $\alpha$ is highly expressed in astrocytes, but not in microglia in the SNpc of monkeys (Figure 5). TNF- $\alpha$ immuno-reactivity is observed very close to GFAP expression in reactive astrocytes (Figure $5 e$ ), which suggests that TNF- $\alpha$ synthesis and/or release may be intimately linked with the astrocyte cytoskeleton. TNF- $\alpha$-expressing astrocytes could also be seen in control animals, but their expression and percentage increased in Parkinsonian monkeys (Figure 5f).

Recent experiments performed in vitro have concluded that microglial cells are the initial responders to inflammation and suggest that astrocytes may amplify the production of neurotoxic factors after microglial activation. ${ }^{29}$ These findings are consistent with the idea that the release of IFN- $\gamma$ by microglial cells is important for the initiation and maintenance of microglial and astroglial activation in combination with TNF- $\alpha$. Importantly, increasing evidence points to the TNF- $\alpha$ released by astrocytes as having a deleterious impact on dopaminergic neurons, as previously described in vitro, ${ }^{30}$ stimulating the TNF- $\alpha \mathrm{R}$ present in the neuron membrane. ${ }^{31}$ Our results in chronic Parkinsonian monkeys, however, revealed that IFN- $\gamma$ correlates more strongly with dopaminergic loss than TNF- $\alpha$, suggesting a prominent role for IFN- $\gamma$ in cell death.

We conclude that IFN- $\gamma$ and TNF- $\alpha$ are clearly crucial players in microglial and astroglial activation in Parkinsonism and may be critical factors in the local perpetuation of glial activation in the SNpc, contributing to dopaminergic neuronal degeneration and motor impairment. This strongly suggests that targeting both cytokines may be a suitable therapy for reducing this glial-mediated inflammation in $\mathrm{PD}$.

From a clinical point of view, an abundance of data show that anti-inflammatory treatment may be beneficial for 
Parkinsonian patients. ${ }^{32}$ Neuropathological examinations suggest that persistent glial activation in humans may be responsible of exacerbating the inflammatory environment and contribute to neuronal degeneration. ${ }^{1,3}$ Some antiinflammatory drugs have been reported as having an impact on the development of the disease ${ }^{32}$ and, interestingly, a polymorphism, precisely in the HLA-DR gene, has recently been described as a putative gene that may affect the susceptibility to $\mathrm{PD} .^{33}$ It is therefore important to tackle the exacerbated glial response, but only targeting the precise mechanisms. In particular, the development of specific antibodies that avert cytokine activity represents a promising therapy for many CNS disorders. ${ }^{34}$ We propose that the manipulation of both these pro-inflammatory cytokines, IFN- $\gamma$ and TNF- $\alpha$, which seem to contribute to dopaminergic neuronal degeneration, could well be relevant for PD therapy in the near future.

\section{Materials and Methods}

Parkinsonian monkeys. The present study uses blood samples and brain tissue from a colony of chronic Parkinsonian macaques (Macaca fascicularis), which have been studied for several years in our Primate Unit. All studies were carried out in accordance with the Guidelines of the European Convention for the protection of vertebrate animals used for experimental and other scientific purposes of the Council of Europe of 2006, the Helsinki Declaration, the International Primatological Society Guidelines and the Guide for the Care and Use of Laboratory Animals (NIH Guide, revised 1996). Samples obtained from 20 young adult animals of both sexes were analyzed. A total of 14 animals at 4 years of age were treated with low weekly intravenous doses of MPTP $(0.3 \mathrm{mg} / \mathrm{kg})$ according to previous protocols. ${ }^{35}$ As each individual has a very different susceptibility to MPTP, the number of injections varied depending on the systemic response to the toxin and the motor score reached. The treatment with MPTP was stopped when: (1) a stable Parkinsonism was achieved, or (2) when the individual displayed a systemic response that was considered potentially lethal or (3) when new injections do not affect the motor score (Table 1). None of them received L-DOPA or dopaminergic agonizts. The animals were observed by different researchers after each dose and as the Parkinsonian syndrome progressed. Motor symptoms were assessed using a previously described scale ranging from 0 to $25{ }^{35}$ The degree of disability normally increased with every new injection and remained stable for years. Animals showing evident Parkinsonian symptoms after MPTP injection as well as clear impairment of their motor score were classified as Parkinsonian. Animals with no apparent Parkinsonian symptoms after MPTP administration were considered asymptomatic. Non-MPTP-treated animals were grouped as controls (Figure 1 and Table 1). This classification provided a population of subjects similar to the scenario that occurs in humans, where symptomatic patients show more than $80 \%$ dopaminergic loss, while some individuals remain asymptomatic despite a starting neurodegenerative process. We were not able to group the animals into smaller subgroups (e.g. degree of Parkinsonism or time of survival after MPTP administration) because the sample would have been too small to ascertain statistically significant differences. Animals were killed from 1 to 5 years after the last MPTP administration (Table 1).

MPTP mice. Ten-week-old male knockout mice B6.129S7-Ifng ${ }^{t m 1 T s} / \mathrm{J}$, TNF- $\alpha$

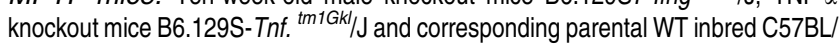
$6 \mathrm{~J}$ mice were purchased from JaxMice (The Jackson Laboratory, Bar Harbor, ME, USA). The mice were housed in a special room with adequate temperature $\left(21^{\circ} \mathrm{C}\right)$ and $12 \mathrm{~h}$ day-night cycles. Mice were injected (by intraperitoneal injection) either with a single dose of MPTP $(20 \mathrm{mg} / \mathrm{kg})$ or the same volume of saline and killed $24 \mathrm{~h}$ after the single injection ( $n=6$ per group). All studies were carried out in accordance with the Guidelines of the European Convention for the protection of vertebrate animals used for experimental and other scientific purposes of the Council of Europe of 2006, the Helsinki Declaration and the IACUC of the University of Murcia.

\section{ELISA determination of IFN- $\gamma$ and TNF- $\alpha$}

Monkey serum extraction. IFN- $\gamma$ and TNF- $\alpha$ concentrations in monkey blood serum were determined by ELISA detection kit (human IFN- $\gamma$ and human TNF- $\alpha$, e-biosciences, San Diego, CA, USA). To withdraw the blood samples, 2 days before killing, the monkeys were restrained in their own cage by a movable back wall and the extraction was made through the saphenous vein using a sterile $5 \mathrm{ml}$ syringe and intravenous needle at between 09:00 and 10:00 hours. No sedative was used to take the samples. The serum samples were obtained by centrifugation of the individual blood samples at 3600 r.p.m. for $10 \mathrm{~min}$ at room temperature. The resultant supernatant was aliquoted and stored at $-80^{\circ} \mathrm{C}$ until analysis.

Mouse serum extraction. IFN- $\gamma$ and TNF- $\alpha$ concentrations in mouse blood serum were determined by ELISA detection kit (mouse IFN- $\gamma$ and mouse TNF- $\alpha$, e-biosciences). To withdraw the blood samples, mice were anesthetized $24 \mathrm{~h}$ after MPTP injection with ketamine/xylazine for perfusion fixation. Before the perfusion, blood was obtained by intra-cardial extraction. The serum samples were obtained by centrifugation of the individual blood samples at 3600 r.p.m. for $10 \mathrm{~min}$ at room temperature. The resultant supernatant was doubly concentrated using a centrifugal filter device (Microcon YM-10, Millipore, Bedford, MA, USA) and pools of three mice were made to reach perceptive values. Serum samples were stored at $-80^{\circ} \mathrm{C}$ until analysis.

ELISA protocol. Samples from both mice and monkeys were processed with the following ELISA protocol. The 96-well microplates were coated with the capture antibody overnight at $4^{\circ} \mathrm{C}$. The plates were then washed three times with a washing buffer (PBS $+0.05 \%$ Tween 20 ), and $100 \mu$ l of a blocking buffer were added to each well before incubating for $1 \mathrm{~h}$ at room temperature. Subsequently, the plates were incubated with standards and appropriate dilution of the samples for $1 \mathrm{~h}$ at room temperature (hemolyzed serum samples were discarded). After five washes, the secondary antibody was added to the wells, and the plates were again incubated for $1 \mathrm{~h}$ at room temperature. The plates were then washed seven more times and incubated with revealing solution for $15 \mathrm{~min}$. The reaction was stopped by adding $50 \mu \mathrm{l}$ of $2 \mathrm{~N} \mathrm{H}_{2} \mathrm{SO}_{4}$. The absorbance of each well was measured at $450 \mathrm{~nm}$, using a microplate reader.

\section{Tissue and specific staining}

Monkeys. The monkeys were killed with a lethal pentobarbital injection after ketamine anesthesia 1, 2 or 5 years after the last MPTP dose (Table 1). The brains were then removed and one brain hemisphere was rapidly frozen with dry ice and stored at $-80^{\circ} \mathrm{C}$ for western blot analysis. The other half was fixed for 3 days in $4 \%$ paraformaldehyde dissolved in $0.1 \mathrm{M}$ phosphate buffer. The fixed mesencephalon was sectioned into $40 \mu \mathrm{m}$ thick serial sections (Microm, HM400). Series of sections regularly spaced at intervals of $1440 \mu$ m were stained for tyrosine hydroxylase (TH) (sheep polyclonal antibody 1:500; Chemicon, Temecula, CA, USA) to quantify the loss of dopaminergic neurons in the MPTP-intoxicated monkeys; for GFAP (rabbit polyclonal antibody 1:500; Chemicon) to analyze the putative astrogliosis in the SNpc of the Parkinsonian monkeys; for Iba-1 (rabbit polyclonal antibody 1:500; Wako, Chuo-Ku, Osaka, Japan) to determine the population and phenotype of microglial cells; for human leukocyte antigen-DR (HLA-DR) $\alpha$-chain CR3/43 clone; (mouse monoclonal antibody 1:50; Dako, Carpinteria, CA, USA) to observe the microglial activation. Antibodies were also used to detect the expression of cytokines in the SNpc: anti-human IFN- $\gamma$ (mouse monoclonal, 1:100, R\&D, Minneapolis, MN, USA) and anti-human TNF- $\alpha$ (mouse monoclonal, $1: 100, R \& D$ ). We also used specific antibodies to detect IFN- $\gamma$ receptor (IFN- $\gamma \mathrm{R}$ ) (mouse monoclonal antibody 1:100; Fitzgerald Industries International, Acton, MA, USA) and phosphorylated STAT1 (pSTAT1) (mouse monoclonal antibody 1:100; Invitrogen, Carlsbad, CA, USA). Sections from all the animals were stained simultaneously and under the same experimental conditions.

Mice. One day after MPTP injection, mice were anesthetized intraperitoneally with an overdose of ketamine $(50 \mathrm{mg} / \mathrm{kg})$ and xylazine $(50 \mathrm{mg} / \mathrm{kg})$ and perfused-fixed with oxygenated Tyrode's solution followed by $4 \%$ paraformaldehyde in PBS. Brain tissue was removed and post-fixed for $48 \mathrm{~h}$ before sectioning and further analysis. All animal experiments were performed after previous approval and conformed to the policies and procedures of the University of Murcia.

The mesencephalon and the striatum were sectioned into $40 \mu \mathrm{m}$ thick serial sections (Vibratome, Leica Microsystem, Wetzlar, Germany). Series of regularly spaced sections were stained for tyrosine hydroxylase $(\mathrm{TH})$ (sheep polyclonal antibody 1:500; Chemicon); for GFAP to observe astroglial activation (rabbit monoclonal antibody 1:500; Chemicon); for F4/80 (rat antibody 1:50; Serotec, Kidlington, UK) to detect microglial activation and for Iba-1 (rabbit polyclonal antibody 1:500; Wako) to study the microglial phenotype.

\section{Immunohistochemistry and immunofluorescence}

$D A B$ detection. For immunohistochemistry, sections of the SNpc $(40 \mu \mathrm{m})$ were used to detect specific cells. Endogenous peroxidase activity was inhibited with $0.3 \% \mathrm{H}_{2} \mathrm{O}_{2}$ and non-specific $\mathrm{Fc}$ binding sites were blocked with $10 \%$ horse serum. 
Sections were incubated for $48 \mathrm{~h}$ (room temperature, constant shaking) with primary antibody (see above) diluted in PBS containing $1 \%$ horse serum, $0.5 \%$ Triton X-100 and $0.1 \%$ sodium azide. Sections were incubated for $4 \mathrm{~h}$ in secondary antibody diluted in antibody solution. Antibody binding was detected with the avidin-biotin peroxidase ABC kit (Vectastain, Vector Labs, Burlingame, CA, USA). Sections were mounted on gelatin-coated slides and dehydrated in a graded ethanol series and xylene before being coverslipped.

Immunofluorescence. For immunofluorescence, $40 \mu \mathrm{m}$ sections were treated with $0.5 \%$ citrate buffer $\left(65^{\circ} \mathrm{C}\right.$, with constant shaking) for $30 \mathrm{~min}$ to maximize antibody penetration into the tissue. Non-specific Fc binding sites were blocked with $10 \%$ horse serum, and sections were incubated for $48 \mathrm{~h}$ (room temperature, constant shaking) with primary antibody diluted in PBS containing $1 \%$ horse serum, $0.5 \%$ Triton X-100 and $0.1 \%$ sodium azide. Sections were incubated for $4 \mathrm{~h}$ in labeled secondary antibody and, after PBS washes, sections were incubated with DAPI solution (Molecular Probes, Carlsbad, CA, USA) $(1: 1000)$ in $1 \times$ PBS for $30 \mathrm{~min}$. Sections were then washed, mounted and examined to quantify the fluorescently labeled cells by conventional microscopy (Zeiss Axioplan 2, Standort Götingen, Germany), or using confocal microscopy (Leica DMIRE2, Wetzlar, Germany). Appropriate secondary antibodies were used: Alexa 488-conjugated and Alexa 594-conjugated (1:1000) (Molecular Probes).

Histological quantification. SNpc was defined according to the Monkey and Mouse Brain Atlas. ${ }^{36,37}$ DAB or fluorescently labeled cells were quantified in serial coronal sections from each animal. The number of cells was estimated by optical fractionator probe using a computer assisted image analysis system with a Zeiss Axioplan 2 microscope connected to a digital camera. The region of interest was traced using the $\times 1.25$ objective. The number of cells was measured in $200 \times 200 \mu \mathrm{m}$ dissectors covering the surface of the analyzed region. Labeled cells were counted using the $\times 40$ objective and counting frames over the delineated area of the SNpc in each section (optical fractionator). Two representative sections of the SNpc were used for each stain in monkey brains. These representative sections were chosen according to the criteria previously defined by Olzewsky and Baxter. ${ }^{38}$ The sections contained the ventrolateral area of the SNpc (in primates corresponding to the $\alpha+\beta$ area at the level of the III cranial nerve output), which is known to show the highest degree of dopaminergic loss and glial activation in humans ${ }^{39}$ and non-human primates. ${ }^{35}$ Four sections of the SNpc were used for each stain in mouse brain. The data are expressed as the density of cells per $\mu \mathrm{m}^{3}$ in each anatomical region analyzed. Results are expressed as the mean \pm S.E.M.

Confocal analysis. Brain sections were examined using a Leica DMIRE2 confocal microscope with the $\times 63$ oil objective and Leica Confocal Software (Leica Microsystems, Wetzlar, Germany). A series range for each section was set by determining an upper and lower threshold using the $Z / Y$ position for spatial image series (for further details see previous publications ${ }^{40}$ ). Images can be illustrated as they appear throughout the stack of sections as a simple $0.5 \mu \mathrm{m}$ layer or as a transparency of all layers merged together.

Quantification of activated glial phenotype. The activated glial state was characterized by the expression of specific reactive proteins as described below (HLA-DR or F4/80 for human or mice microglia, respectively, and GFAP for astroglia), but also according to the change of phenotype (See Supplementary Figure 6). To study the glial phenotype, serial sections along the SNpc from monkeys or mice were stained by immunofluorescence to observe microglial (Iba-1) or astroglial (GFAP) cells. Sections were scanned with confocal microscope as described above and primary and secondary branches were quantified along the $z$ axes in more than 10 cells per animal (more than 50 cells per group). Primary branches were considered as the first ramification emerging from the cell body and secondary branches as the ramification emerging from the primary branches. The microglial or astroglial area was quantified using confocal images of Iba-1 or GFAP. Scanned confocal planes of $0.5 \mu \mathrm{m}$ containing Iba-1 or GFAP-labeled cells were processed with Image-J image software (National Institute of Health, Bethesda, MD, USA) to obtain a black and white image. The area occupied by 50 microglial cells of the SNpc of each animal was measured in these processed images. The area occupied by astroglial cells was not measured in monkeys because their processes were completely intermingled and the software was unable to distinguish and define each individual cell unit. All quantifications were made blindly by two different researchers (CMR and MEM).

\section{Western immunoblot}

Primary antibodies. To test the specificity of the antibodies used to detect IFN- $\gamma$ and TNF- $\alpha$ in the SNpc of monkeys, a western immunoblot was performed with anti TNF- $\alpha$, diluted 1:200 (R\&D systems) and Mouse anti IFN- $\gamma$, diluted 1:200 (R\&D systems). GAPDH antibody was used to determine the housekeeping of each sample (mouse anti GAPDH, 1:500, Chemicon)

Preparation of tissue extracts. The SNpc from the frozen half of the tissue of the monkeys kept at $-80^{\circ} \mathrm{C}$ (see details above) was dissected according to the appropriate coordinates given by the monkey brain atlas, ${ }^{37}$ using a punching device designed in our lab of $0.5 \mathrm{~cm}$ internal diameter. Tissues were immediately homogenized with a disposable pellet pestle (Sigma-Aldrich, St. Louis, MO, USA) in RIPA buffer, containing $50 \mathrm{mM}$ tris/ $\mathrm{HCl} \mathrm{pH} 7.6,150 \mathrm{mM} \mathrm{NaCl}, 1 \mathrm{mM}$ EDTA, $1 \%$ SDS, $1 \%$ Triton X-100, 1x cocktail inhibitor (Sigma-Aldrich), $1 \mathrm{mM}$ PMSF, $0.2 \mathrm{mM}$ $\mathrm{Na}_{3} \mathrm{VO}_{4}$ and $1 \mathrm{mM} \mathrm{NaF}$. After centrifugation $\left(15000 \times \mathrm{g}\right.$ for $15 \mathrm{~min}$ at $\left.4^{\circ} \mathrm{C}\right)$, a specific volume of supernatant was analyzed to determine the total concentration of the protein in the sample using the Micro BCA kit (Pierce, Rockford, IL, USA). Other aliquots of the samples were mixed with $4 \times$ reducing loading buffer $(200 \mathrm{mM}$ Tris/ $\mathrm{HCl} \mathrm{pH} 6.8,4 \%$ SDS, $30 \%$ glycerol, $4 \% \beta$-mercaptoethanol, $4 \%$ blue bromophenol), boiled for $3 \mathrm{~min}$ and stored at $-20^{\circ} \mathrm{C}$ until use.

Electrophoresis and immunoblotting. For each sample, $80 \mu \mathrm{g}$ of proteins were separated on $15 \%$ SDS-polyacrylamide gels. Molecular mass standard (ColorBurst, Sigma-Aldrich) containing the precisely sized recombinant proteins of $210,90,65,40,30,20,13,8 \mathrm{kda}$, positive controls of human recombinant TNF- $\alpha$ $(80 \mathrm{ng}$ ) or human recombinant IFN- $\gamma(80 \mathrm{ng})$ (R\&D systems), and the samples of the $\mathrm{SNpc}$ were run in the same gel and transferred onto a nitrocellulose membrane. The samples were run at constant voltage $(200 \mathrm{mV})$ room temperature (RT) for $1 \mathrm{~h}$.

After electrophoresis, protein samples were transferred onto a nitrocellulose membrane using a transfer buffer $(25 \mathrm{mM}$ Tris/ $/ \mathrm{HCl}, 192 \mathrm{mM}$ glycine, $0.1 \%$ SDS, $20 \%$ methanol). Pounceau S staining (Bio-Rad, Hercules, CA, USA) was used to verify equal protein loading in all the lanes.

Non-specific biding sites were blocked by incubation in $5 \%$ dry milk diluted in TTBS 1X (20 mM tris/ $\mathrm{HCl} \mathrm{pH} \mathrm{7.5,500} \mathrm{mM} \mathrm{NaCl,} \mathrm{0.05 \%} \mathrm{tween-20)} \mathrm{for} 2 \mathrm{~h}$ at RT. The membranes were incubated overnight at $4{ }^{\circ} \mathrm{C}$ in the primary antibody diluted in $3 \%$ BSA, $0.05 \% \mathrm{NaN}_{3}$, in TTBS $1 \mathrm{x}$. After rinsing twice with TTBS $1 \times$ and thrice with $2.5 \%$ dry milk in TTBS $1 \mathrm{X}$, the membranes were incubated for $1 \mathrm{~h}$ at $\mathrm{RT}$ in $\mathrm{ECL}$ sheep anti mouse IgG, horseradish peroxidase conjugated secondary antibody (GE healthcare, Little Chalfont, UK) diluted 1:5000 in 2.5\% dry milk in TTBS $1 \times$. Antibody binding sites were revealed using ECL plus the western blotting detection system (GE healthcare). The intensity of the bands was evaluated by densitometric analysis using ImageJ 1.41 software. The optical density of each protein band was normalized against the optical density of the GAPDH band used as internal standard on the same lane. For each independent experiment, the differences between the experimental groups were expressed as treated/control. The graphs represent the average of the ratios calculated from five independent experiments \pm S.E.M.

Statistical analysis. Data are expressed as mean \pm S.E.M. Statistical analysis was performed using a t-test or one-way ANOVA test following a posthoc analysis (followed by Dunnet or Tukey multiple comparisons tests). The null hypothesis was rejected for an $\alpha$ risk equal to $5 \%$.

\section{Conflict of interest}

The authors declare no conflict of interest.

Acknowledgements. This work was supported by grants from: the Spanish Ministry of Science and Innovation (FIS PI10 02827; SAF 200407656 C02-02; SAF 2010 21274), Fundación Séneca (FS/05662/PI/07), CIBERNED (Centro de Investigación Biomédica en Red sobre Enfermedades Neurodegenerativas) and the private donation from Mr. Damián Frontera Roig. We would like to thank all the personnel from SAI (Servicio de Apoyo a la Investigación), for the help provided at the University of Murcia, especially María García. The authors would also like to thank Mr. P. Thomas for comments and language suggestions on this manuscript. This work is dedicated in the memory of Professor Dr. Luis María Gonzálo-Sanz (6 September 1927-22 March 2009).

\section{Author contributions}

$\mathrm{CB}$ designed and performed the research, analyzed the data and wrote the paper, CMR performed the IHC and ELISA analysis and contributed to the histological quantifications, VA performed the western blot analysis, AG contributed to the IHC and western blot analysis, FR contributed to the manipulation of the animals, DA contributed to the ELISA analysis, MEM contributed to the histological quantifications, VP and EF contributed to the manipulation and care of the animals and MTH designed the research and contributed to writing the paper. 
1. McGeer PL, Itagaki S, Boyes BE, McGeer EG. Reactive microglia are positive for HLA-DR in the substantia nigra of Parkinson's and Alzheimer's disease brains. Neurology 1988; 38: 1285-1291.

2. Forno LS, DeLanney LE, Irwin I, Di Monte D, Langston JW. Astrocytes and Parkinson's disease. Prog Brain Res 1992; 94: 429-436.

3. Langston JW, Forno LS, Tetrud J, Reeves AG, Kaplan JA, Karluk D. Evidence of active nerve cell degeneration in the substantia nigra of humans years after 1-methyl-4-phenyl1,2,3,6-tetrahydropyridine exposure. Ann Neurol 1999; 46: 598-605.

4. McGeer PL, Schwab C, Parent A, Doudet D. Presence of reactive microglia in monkey substantia nigra years after 1-methyl-4-phenyl-1,2,3,6-tetrahydropyridine administration. Ann Neurol 2003; 54: 599-604.

5. Barcia C, Sanchez Bahillo A, Fernandez-Villalba E, Bautista V, Poza YPM, FernandezBarreiro A et al. Evidence of active microglia in substantia nigra pars compacta of Parkinsonian monkeys 1 year after MPTP exposure. Glia 2004; 46: 402-409.

6. Benveniste EN, Kwon J, Chung WJ, Sampson J, Pandya K, Tang LP. Differential modulation of astrocyte cytokine gene expression by TGF-beta. J Immunol 1994; 153 5210-5221.

7. Dickson DW, Lee SC, Mattiace LA, Yen SH, Brosnan C. Microglia and cytokines in neurological disease, with special reference to AIDS and Alzheimer's disease. Glia 1993 7: 75-83.

8. Mount MP, Lira A, Grimes D, Smith PD, Faucher S, Slack R et al. Involvement of interferongamma in microglial-mediated loss of dopaminergic neurons. J Neurosci 2007; 27: 3328-3337.

9. Reale M, larlori C, Thomas A, Gambi D, Perfetti B, Di Nicola M et al. Peripheral cytokines profile in Parkinson's disease. Brain Behav Immun 2009; 23: 55-63.

10. Mogi M, Harada M, Riederer P, Narabayashi H, Fujita K, Nagatsu T. Tumor necrosis factoralpha (TNF-alpha) increases both in the brain and in the cerebrospinal fluid from Parkinsonian patients. Neurosci Lett 1994; 165: 208-210.

11. Sriram K, Matheson JM, Benkovic SA, Miller DB, Luster MI, O'Callaghan JP. Mice deficient in TNF receptors are protected against dopaminergic neurotoxicity: implications for Parkinson's disease. FASEB J 2002; 16: 1474-1476.

12. Ferger $B$, Leng A, Mura A, Hengerer $B$, Feldon J. Genetic ablation of tumor necrosis factoralpha (TNF-alpha) and pharmacological inhibition of TNF-synthesis attenuates MPTP toxicity in mouse striatum. J Neurochem 2004; 89: 822-833.

13. Barcia C, de Pablos V, Bautista-Hernandez V, Sanchez-Bahillo A, Bernal I, FernandezVillalba $E$ et al. Increased plasma levels of TNF-alpha but not of IL1-beta in MPTP-treated monkeys one year after the MPTP administration. Parkinsonism Relat Disord 2005; 11 435-439.

14. Vazquez-Claverie M, Garrido-Gil P, San Sebastian W, Izal-Azcarate A, Belzunegui S, Marcilla I et al. Acute and chronic 1-methyl-4-phenyl-1,2,3,6-tetrahydropyridine administrations elicit similar microglial activation in the substantia nigra of monkeys. J Neuropathol Exp Neurol 2009; 68: 977-984.

15. Hashioka S, Klegeris A, Schwab C, McGeer PL. Interferon-gamma-dependent cytotoxic activation of human astrocytes and astrocytoma cells. Neurobiol Aging 2009; 30: 1924-1935.

16. Tsuda M, Masuda T, Kitano J, Shimoyama H, Tozaki-Saitoh H, Inoue K. IFN-gamma receptor signaling mediates spinal microglia activation driving neuropathic pain. Proc Natl Acad Sci USA 2009; 106: 8032-8037.

17. Vega C, Pellerin L, Dantzer R, Magistretti PJ. Long-term modulation of glucose utilization by IL-1 alpha and TNF-alpha in astrocytes: $\mathrm{Na}+$ pump activity as a potential target via distinct signaling mechanisms. Glia 2002; 39: 10-18

18. Kipp M, Karakaya S, Johann S, Kampmann E, Mey J, Beyer C. Oestrogen and progesterone reduce lipopolysaccharide-induced expression of tumour necrosis factoralpha and interleukin-18 in midbrain astrocytes. J Neuroendocrinol 2007; 19: 819-822.

19. Lung $\mathrm{HL}$, Leung $\mathrm{KN}$, Stadlin $\mathrm{A}, \mathrm{Ma} \mathrm{CM}$, Tsang $\mathrm{D}$. Induction of tumor necrosis factor receptor type 2 gene expression by tumor necrosis factor-alpha in rat primary astrocytes. Life Sci 2001; 68: 2081-2091.

20. Scalzo P, Kummer A, Cardoso F, Teixeira AL. Increased serum levels of soluble tumor necrosis factor-alpha receptor-1 in patients with Parkinson's disease. J Neuroimmunol 2009; 216: 122-125.

21. Godoy MC, Tarelli R, Ferrari CC, Sarchi MI, Pitossi FJ. Central and systemic IL-1 exacerbates neurodegeneration and motor symptoms in a model of Parkinson's disease. Brain 2008; 131 (Part 7): 1880-1894.
22. Kurkowska-Jastrzebska I, Balkowiec-Iskra E, Ciesielska A, Joniec I, Cudna A Zaremba $\mathrm{MM}$ et al. Decreased inflammation and augmented expression of trophic factors correlate with MOG-induced neuroprotection of the injured nigrostriatal system in the murine MPTP model of Parkinson's disease. Int Immunopharmacol 2009; 9 : 781-791.

23. Luchtman DW, Shao D, Song C. Behavior, neurotransmitters and inflammation in three regimens of the MPTP mouse model of Parkinson's disease. Physiol Behav 2009; 98 130-138.

24. Hebert G, Arsaut J, Dantzer R, Demotes-Mainard J. Time-course of the expression of inflammatory cytokines and matrix metalloproteinases in the striatum and mesencephalon of mice injected with 1-methyl-4-phenyl-1,2,3,6-tetrahydropyridine, a dopaminergic neurotoxin. Neurosci Lett 2003; 349: 191-195.

25. Brochard V, Combadiere B, Prigent A, Laouar Y, Perrin A, Beray-Berthat V et al. Infiltration of $\mathrm{CD} 4+$ lymphocytes into the brain contributes to neurodegeneration in a mouse model of Parkinson disease. J Clin Invest 2009; 119: 182-192.

26. Bogdan $\mathrm{C}$, Schleicher U. Production of interferon-gamma by myeloid cells-fact or fancy? Trends Immunol 2006; 27: 282-290.

27. Puddu P, Fantuzzi L, Borghi P, Varano B, Rainaldi G, Guillemard E et al. IL-12 induces IFN-gamma expression and secretion in mouse peritoneal macrophages. J Immunol 1997 159: 3490-3497.

28. Munder M, Mallo M, Eichmann K, Modolell M. Murine macrophages secrete interferon gamma upon combined stimulation with interleukin (IL)-12 and IL-18: a novel pathway of autocrine macrophage activation. J Exp Med 1998; 187: 2103-2108.

29. Saijo K, Winner B, Carson CT, Collier JG, Boyer L, Rosenfeld MG et al. A Nurr1/CoREST pathway in microglia and astrocytes protects dopaminergic neurons from inflammationinduced death. Cell 2009; 137: 47-59.

30. Downen M, Amaral TD, Hua LL, Zhao ML, Lee SC. Neuronal death in cytokine-activated primary human brain cell culture: role of tumor necrosis factor-alpha. Glia 1999; 28: 114-127.

31. Boka G, Anglade P, Wallach D, Javoy-Agid F, Agid Y, Hirsch EC. Immunocytochemical analysis of tumor necrosis factor and its receptors in Parkinson's disease. Neurosci Lett 1994; 172: 151-154.

32. Chen $\mathrm{H}$, Jacobs E, Schwarzschild MA, McCullough ML, Calle EE, Thun MJ et al. Nonsteroidal antiinflammatory drug use and the risk for Parkinson's disease. Ann neurol 2005; 58: 963-967.

33. Hamza TH, Zabetian CP, Tenesa A, Laederach A, Montimurro J, Yearout D et al. Common genetic variation in the HLA region is associated with late-onset sporadic Parkinson's disease. Nat genet 2010; 42: 781-785.

34. Kopf M, Bachmann MF, Marsland BJ. Averting inflammation by targeting the cytokine environment. Nat rev 2010; 9: 703-718.

35. Herrero MT, Hirsch EC, Kastner A, Ruberg M, Luquin MR, Laguna $\mathrm{J}$ et al. Does neuromelanin contribute to the vulnerability of catecholaminergic neurons in monkeys intoxicated with MPTP? Neuroscience 1993; 56: 499-511.

36. Paxinos GC, Franklin KBJ. The mouse brain in stereotaxic coordinates. Academic Press: New York, 2001.

37. Paxinos G, Xu-Feng H, Toga A. The Rhesus Monkey Brain in Stereotaxic Coordinates. Academic Press: San Diego, 1999.

38. Olzewski J., Baxter D. In: Boyd JD (ed.). Cytoarchitecture of the Human Brainstem S. Karger, Lippincott Company: Philadelphia and Montreal, 1954.

39. Damier P, Hirsch EC, Agid Y, Graybiel AM. The substantia nigra of the human brain. II. Patterns of loss of dopamine-containing neurons in Parkinson's disease. Brain 1999; 122 (Part 8): 1437-1448.

40. Barcia C, Thomas CE, Curtin JF, King GD, Wawrowsky K, Candolfi M et al. In vivo mature immunological synapses forming SMACs mediate clearance of virally infected astrocytes from the brain. J Exp Med 2006; 203: 2095-2107.

Cell Death and Disease is an open-access journal published by Nature Publishing Group. This work is licensed under the Creative Commons Attribution-Noncommercial-No Derivative Works 3.0 Unported License. To view a copy of this license, visit http://creativecommons.org/licenses/by-nc-nd/3.0/

\section{Supplementary Information accompanies the paper on Cell Death and Disease website (http://www.nature.com/cddis)}

